\title{
Modelling of multi layer beam with inter-layer slips
}

\author{
Johannes Natterer \\ Phd candidate, ingineer EPFL \\ Laboratory for timber constructions IBOIS, Ecole Polytechnique fédérale de Lausanne, EPFL \\ Lausanne, Switzerland \\ Yves Weinand \\ Prof. Dr., engineer EPFL, architect ISA \\ Laboratory for timber constructions IBOIS, Ecole Polytechnique fédérale de Lausanne, EPFL \\ Lausanne, Switzerland
}

\section{Summary}

In the early $90^{\text {th }}$ the IBOIS-EPFL developed a new kind of shell structure. The ribs were made with simple planks which are waved together to build a spacial ribbed shell. The first application was the Polydome in 1993, and the most fascinating has been the Expodach in Hannover in year 2000 [1].

However, the calculation and the realization of such structures requires particular knowledge and experience. That is why the construction of such structures is something exceptional. In addition to the anisotropy of material wood, the spatial structure of laminated and screwed beams has a structural anisotropy. They constitute highly unspecified static systems. Currently the engineer does not have any effective method to calculate these kinds of spatial structures, made out of curved screwed lamellate boards. The existing approximations for complex curved structures are not satisfying. The main differences are noticed especially upon the analysis of the stability of structures subject to horizontal loads.

The following article will compare a 6-layered beam with inter-layer slips in different load cases and situations. The beam is composed of 6 planks with a section of $140 / 27 \mathrm{~mm}$. The connections between the layers are screws. The studied parameters are the distance between the connector, the length of the beam and 3 different load cases. A total of 24 elements have been tested and compared between the laboratory test and different theories.

A very important parameter is the stiffness of the connector. Thus additional tests have been made to simulate the stiffness of the screws used. A bi-exponential law has been generated to be used in the theoretical evaluation of the tests.

The actual theories which have been used to simulate the behavior of the sample are gammaMethod of Möhler-Schelling, Appendix F of the Germand standard E-DIN 1052 of Prof.

Kreuzinger, framework systems developed by Kneidl and Hartmann and finally a multi-layer finite element developed at the LSC-EPFL by Prof. Frei and Dr. Krawczyk.

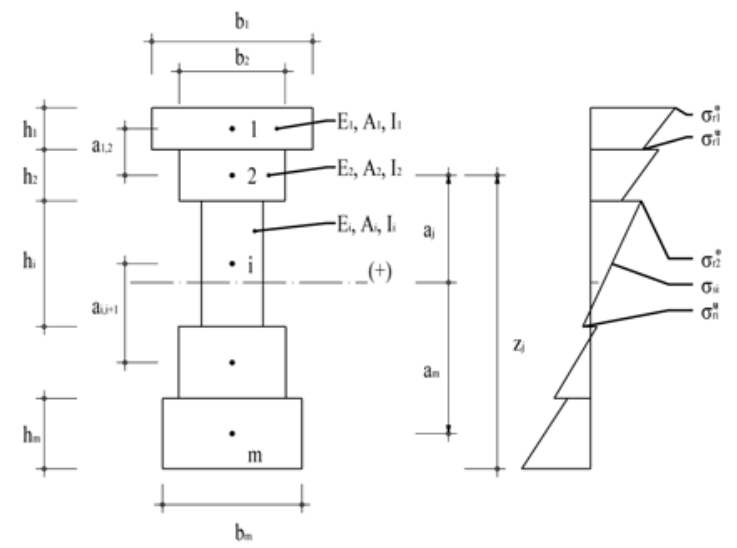

Fig.1. Multi-layered beam by Schelling 


\section{Theories}

The following chapter proposes a brief introduction to the different theories used to analyze a multi layered beam.

\section{$2.1 \gamma$-method}

The $\gamma$-method is the oldest method described in this article. It was developed in 1955 by Prof. Karl Möhler [2] for up to 4-layer poles. This law has been integrated in the German DIN 102 since 1970. Dr. Schelling [3] enlarged the possibility with matricial calculation for a n-layered beam in 1965. The starting assumption was the analysis of the stiffness and so the critical load of a multilayered pole in compression. To define the statical system Shelling admits a sinusoidal transversal load und compression to integrate the stiffness. This method is still a reference. The solution is given as form as matriciel calculation which resolution gives the $\gamma$-factors. The equivalent stiffness is given by Fig.2

$$
I_{e q}=\sum_{i=1}^{m} I_{i}+\sum_{i=1}^{m} \gamma_{i} \cdot \bar{A}_{i} \cdot a_{i}^{2}
$$

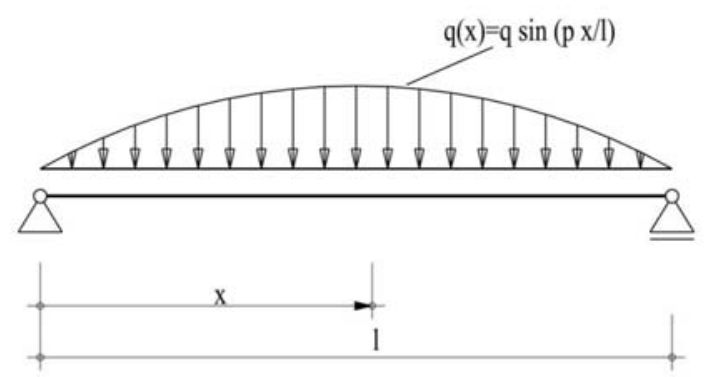

Fig.2. Equivalent stiffness, of the multi layered beam

Fig.3. 2 Statical system

\subsection{Frameworks}

Kneidl and Hartmann [4] proposed different framework models. Those are the most implicit and most reliable to modelise multi layered beams. Each section is represented in the statical system by a beam. In order to hold account of the slip between the layers different possibilities are proposed. The model A just places a small console with the adequate hinge at the end. Model B allows running in finite model programs which do not have the possibility of hinges by adapting the stiffness of the diagonals. Hartmann [4] combined both model to make Model $\mathrm{C}$ by placing the hinges at the end of a console made by diagonals to avoid the local introduction of moments (model A). The solution has a continuous development of the bending moment.

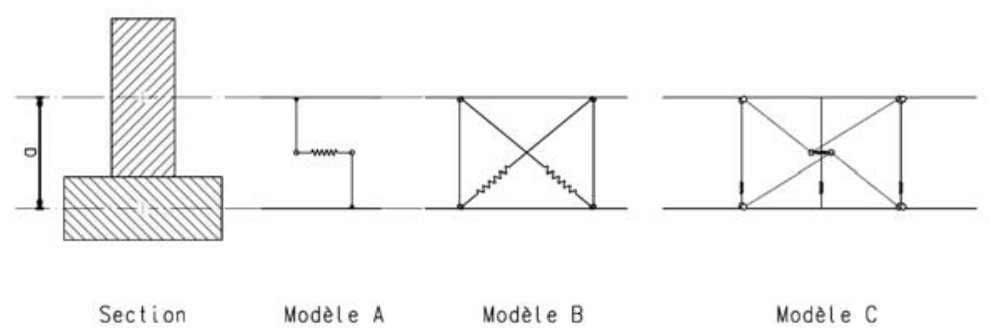

Fig.4. Framework models

These systems are sensible to the inclination of the diagonals and the distance of the the modelised connectors. The ratio between modeled connectors and the thickness of the planks must be smaller than 2.0

\subsection{Analogy procedure}

In 1999, Kreuzinger [6] published the analogy procedure, which separates the rigidity of the self stiffness (beam A) and the translation stiffness (beam B) in two elements. The stiffness of the 
composed section is steered by the shear stiffness S of beam B. A large scale parameter study has been made by Pirazzy[9] for the analyse of beam on three support with continuous load.

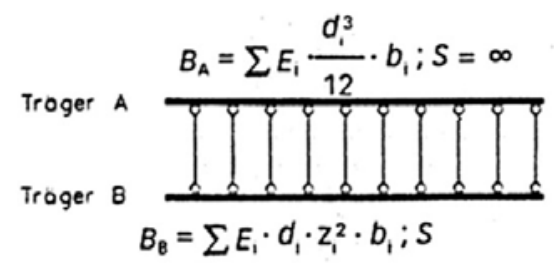

Fig.5. Analogy procedure

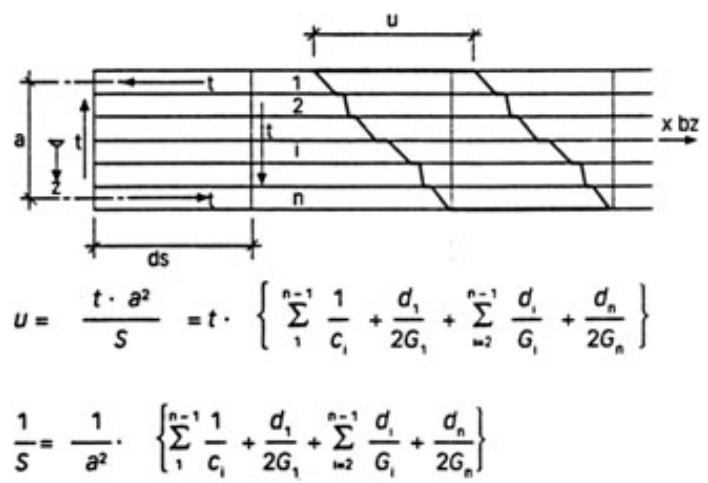

\subsection{Finite element}

In 2006, Dr. Piotr Krawczyk[7] concluded his PhD with the programation of a finite element of multi-layered beams with small interlayer slips on FELINA. This element has $2 n+1$ degrees of freedom (see fig. Fig.6). The degrees of freedom are the displacement of the reference line (u,v), the slip of each interface $\left(g_{i}\right)$ and the rotation of each layer $\left(\theta_{n}\right)$. At the moment the finite element is only in bi-dimensional.

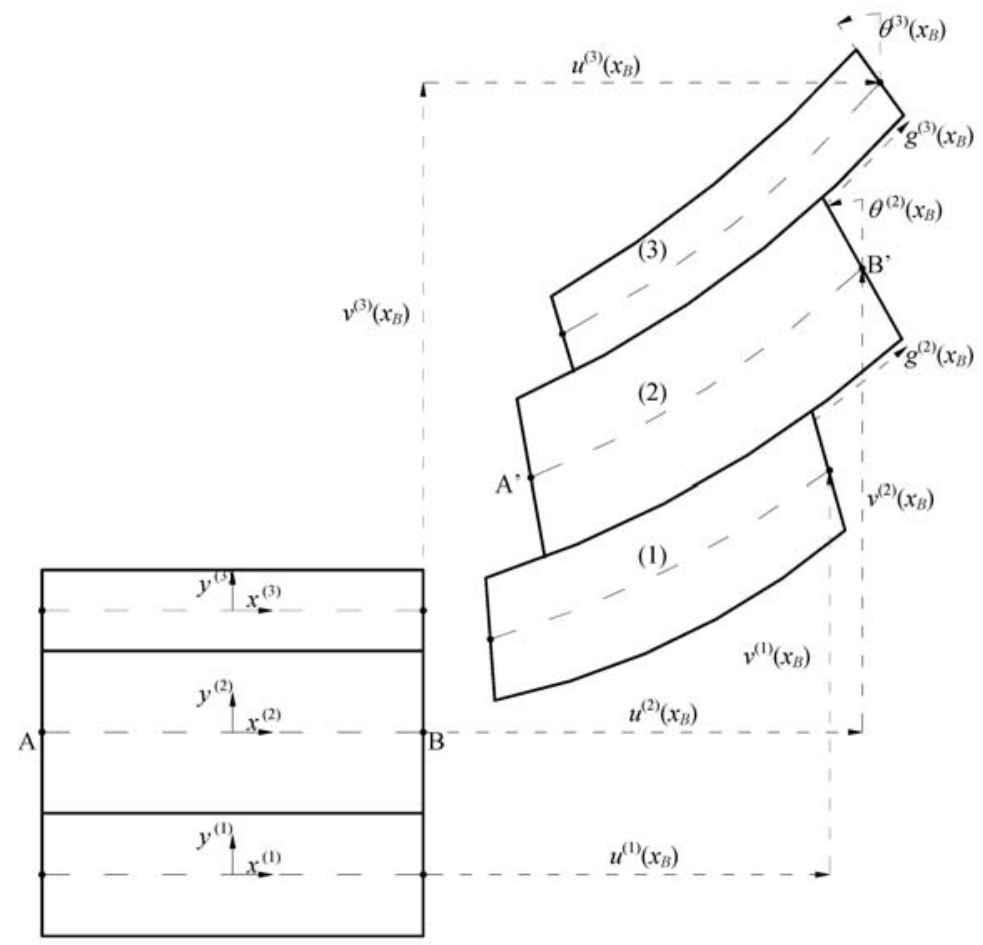

Fig.6. Degrees of freedom of the finite element

\section{Shear stiffness}

A very important input for the modelisation of the 6-layered beam is the stiffness of the joints. In normal case the shear tests are run with direct transmission of the forces. The cases calculated by Johansen [8] and the norms (see Fig.7) are direct transmission of the forces. In cases of multilayered beams the connectors are sheared twice. Pirazzi [9] made a large investigation and settled out a test to improve the stiffness. 

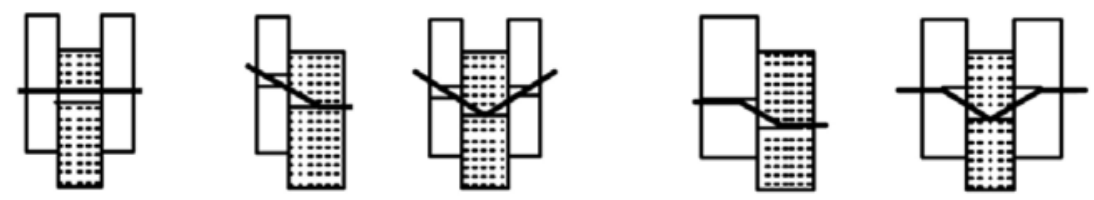

Fig.7. Different failure mechanisms according to DIN 1052[10]

a.

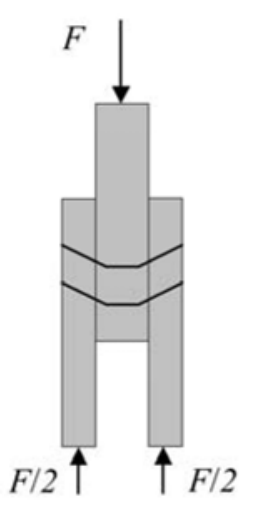

b.

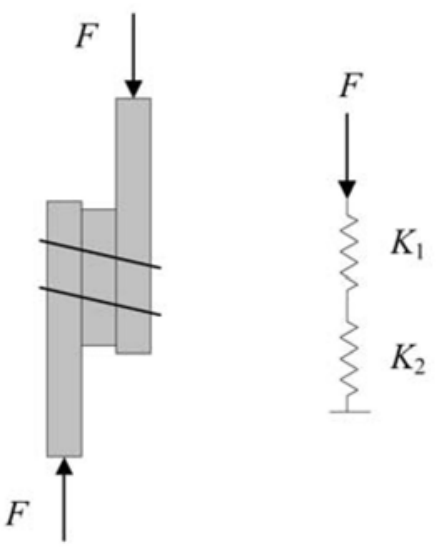

Fig.8. Schematized spring models: a. two-shear connection as standard model;b. double sheared connectors

This test has been slightly changed to avoid eccentricity which induces traction in the connectors. There are many laws to describe the curve charge deformation of the joints. Ehlbeck [12] made a compilation of the existing laws in his book "nailed joints in wood structures". Foshi[11] made a proposal of an exponential bi-linear law, which has been hold back. Several programs allow this form of non-linear behavior of material.

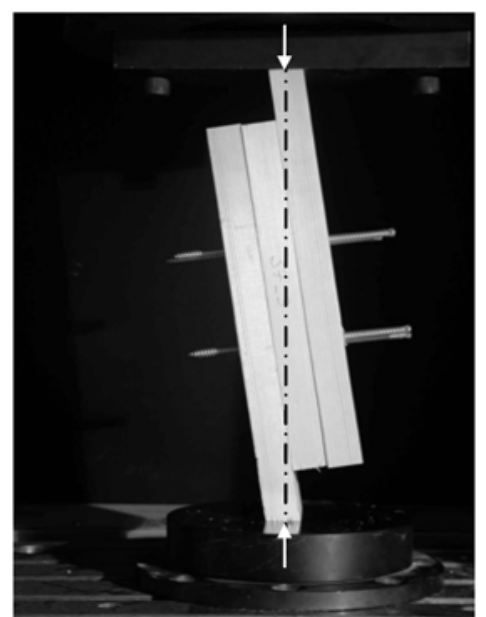

Fig.9. Shear test proposed by Pirazzi
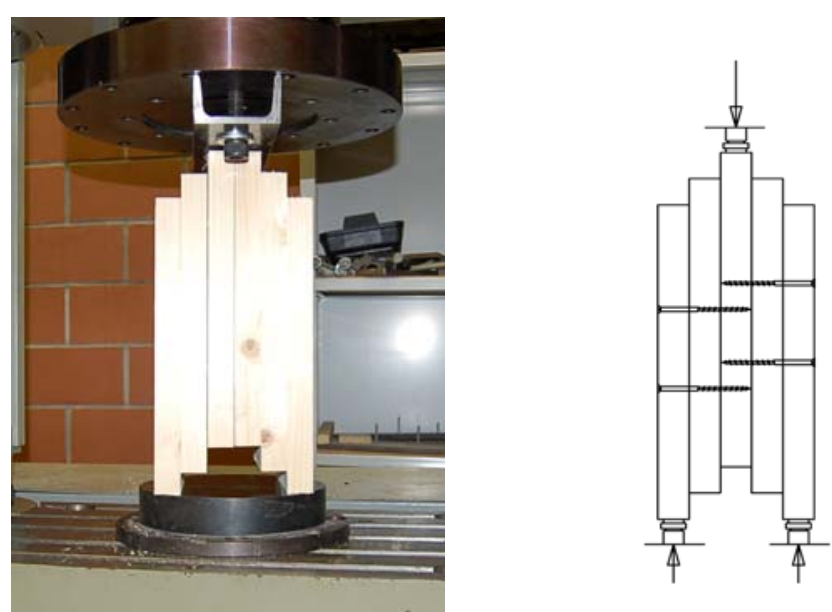

Fig.10. Modified shear test 


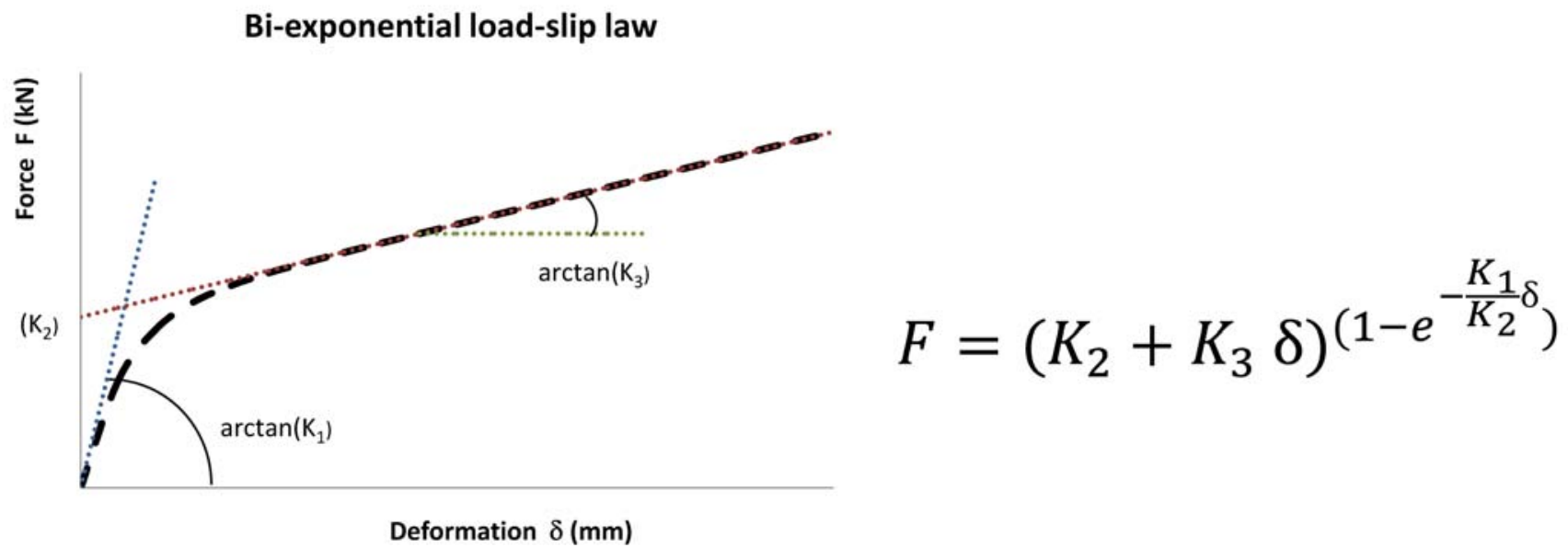

Fig.11.Bi-exponential behaviour

The tests have been made on short and longer samples with 8 and 16 screws. This variation of the length has been made in order to verify the non-relevant influence of the length and the eccentricity on the sample. The following graph (Fig.12) shows the results of the shear test.

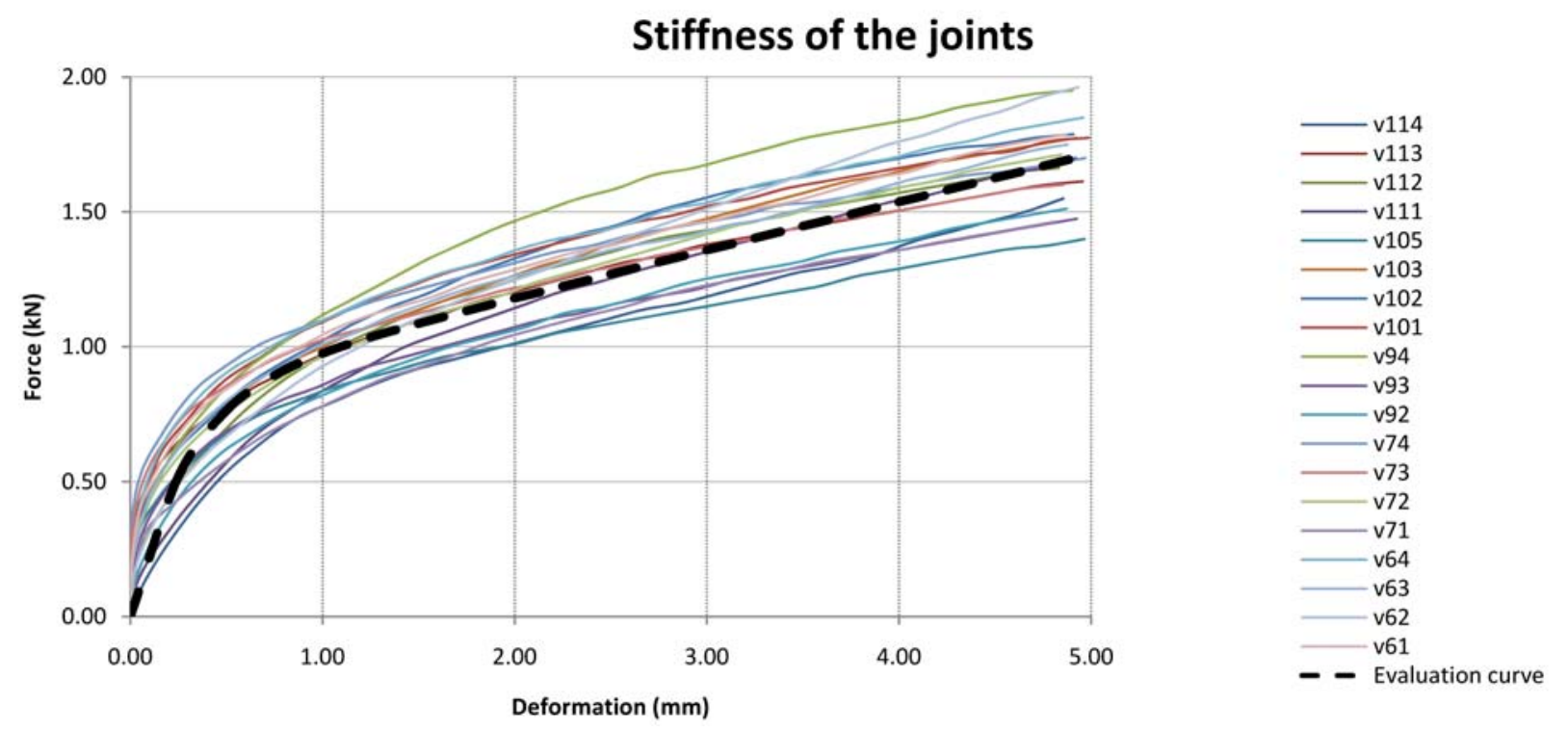

Fig.12. Shear stiffness of the joints with screws $d=4.0, l=80 \mathrm{~mm}$ Assy Ecofast

The following very important points should be stressed:

- The tests have been made with Assy Ecofast from Würth. The shear-stiffness is strong depending of young-modulus of the steal, and not every screw has the same quality.

- The thickness of the planks is $27 \mathrm{~mm}$

- The K-factors of the curve for the evaluation of the tests are made with 6-layered beams and do not include usual safety factors, they should not be applied in practice. 
The factors of the fitted curve are:

$$
\begin{array}{lll}
\mathrm{K}_{1} & = & 2986.6 \mathrm{~N} / \mathrm{mm} \\
\mathrm{K}_{2} & =823.1 \mathrm{~N} \\
\mathrm{~K}_{3} & =178.4 \mathrm{~N} / \mathrm{mm}
\end{array}
$$

The high stiffness of the departure of 2'986.6 N/mm has to be mentioned.

\subsection{Linearization}

Some theories are not possible with the bi-exponential behavior of the stiffness of the joints so it has to be transformed in a linear law. The following graph shows the way to determinate $\mathrm{K}_{\text {ser, }}$, stiffness according to DIN EN 26891.

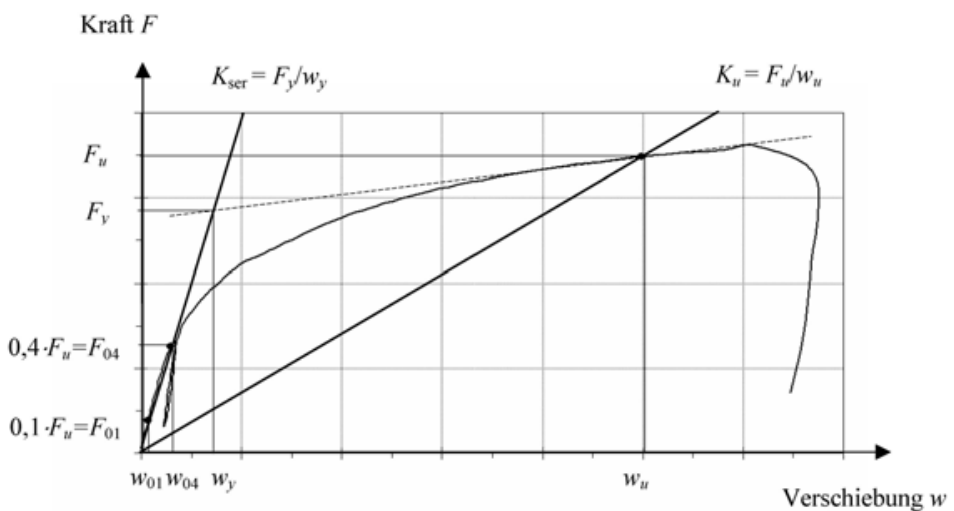

$$
\begin{gathered}
K_{\text {ser }}=\frac{3}{4} \frac{F_{04}}{w_{04}-w_{01}} \\
K_{u}=\frac{F_{u}}{w_{u}}
\end{gathered}
$$

Fig.13. Determination of the rigidity and the load-carrying capacity of a connection based on the characteristic force-deformation curve according to the DIN EN 26891

Using $\mathrm{Fu}=2.0 \mathrm{kN}$ will give following value of stiffness:

$$
K_{\text {ser }}=1^{\prime} 243 \frac{\mathrm{N}}{\mathrm{mm}} \quad K_{u}=303.0 \frac{\mathrm{N}}{\mathrm{mm}}
$$

Fig.14. Result of the linearization, Stiffness at service state $K_{\text {ser }}$ and ultimate state $K_{u}$.

In comparison of the high stiffness of the departure of 2'986.6 N/mm, we lost a little bit of the departure stiffness by making the linearization.

\section{Evaluation}

The previous chapter proposed a brief introduction to the theories of multi-layered beams and shear stiffness of the joints. This chapter shows the evaluation of tests made in the laboratory for timber construction of the EPFL. The test have been made on 6-layered beams with a section 27/140 mm2. The connectors are Assy Ecofast $\mathrm{d}=5.0 \mathrm{~mm}, \mathrm{l}=80 \mathrm{~mm}$. The distance between the connectors is $15 \mathrm{~cm}$ and $30 \mathrm{~cm}$. The lengths of the sample were $3.7 \mathrm{~m}$ and $5.4 \mathrm{~m}$. Two types of load cases were tested and shown in Fig. $15 \mathrm{~b}$ and c. It must be noted that the test flexion-compression is loaded with a constant force and the compression force is increased. The reason of to chose of this load cases is that a previous analyze [13] has shown that in perfect identical condition, the different theories were showing differences up to $30 \%$. 

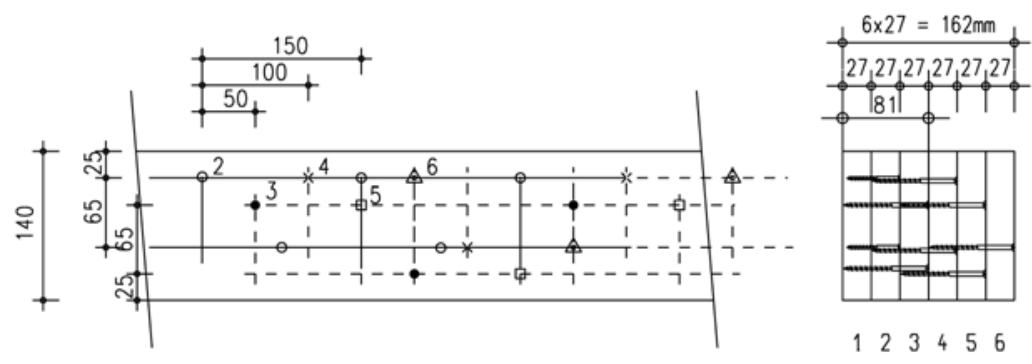

a.

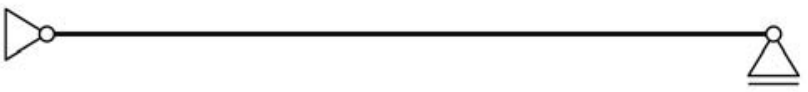

b.

C.

Fig.15.a. Composition of the section $\boldsymbol{b}$. Compression test $\boldsymbol{c}$. Compression-flexion

Following graphic is showing the deflection of the compression test (Fig.15b). The marked curves shows the result of the test. The four other curves are the modelisation with different theories. The applied theories with a linear behavior of the joint (see chap. 3.1) are framework type B, Analogy and Möhler-Schelling. And finally the finite element of Krawczyk allowed a non-linear behavior of the joint. The critical load of the 6-layered pole is about $45 \mathrm{kN}$, all the curves of the theories are below test results, so on the secure size.

The advantage of using the non-linear law can be compared at a normal force of $20 \mathrm{kN}$. The Krawzyk finite element gives a deformation of $10 \mathrm{~mm}$ and $\gamma$-method a deformation $20 \mathrm{~mm}$, and $16 \mathrm{~mm}$ for the analogy. The difference is about $100 \%$ when the pole is charged with a transversal load (Fig.17).

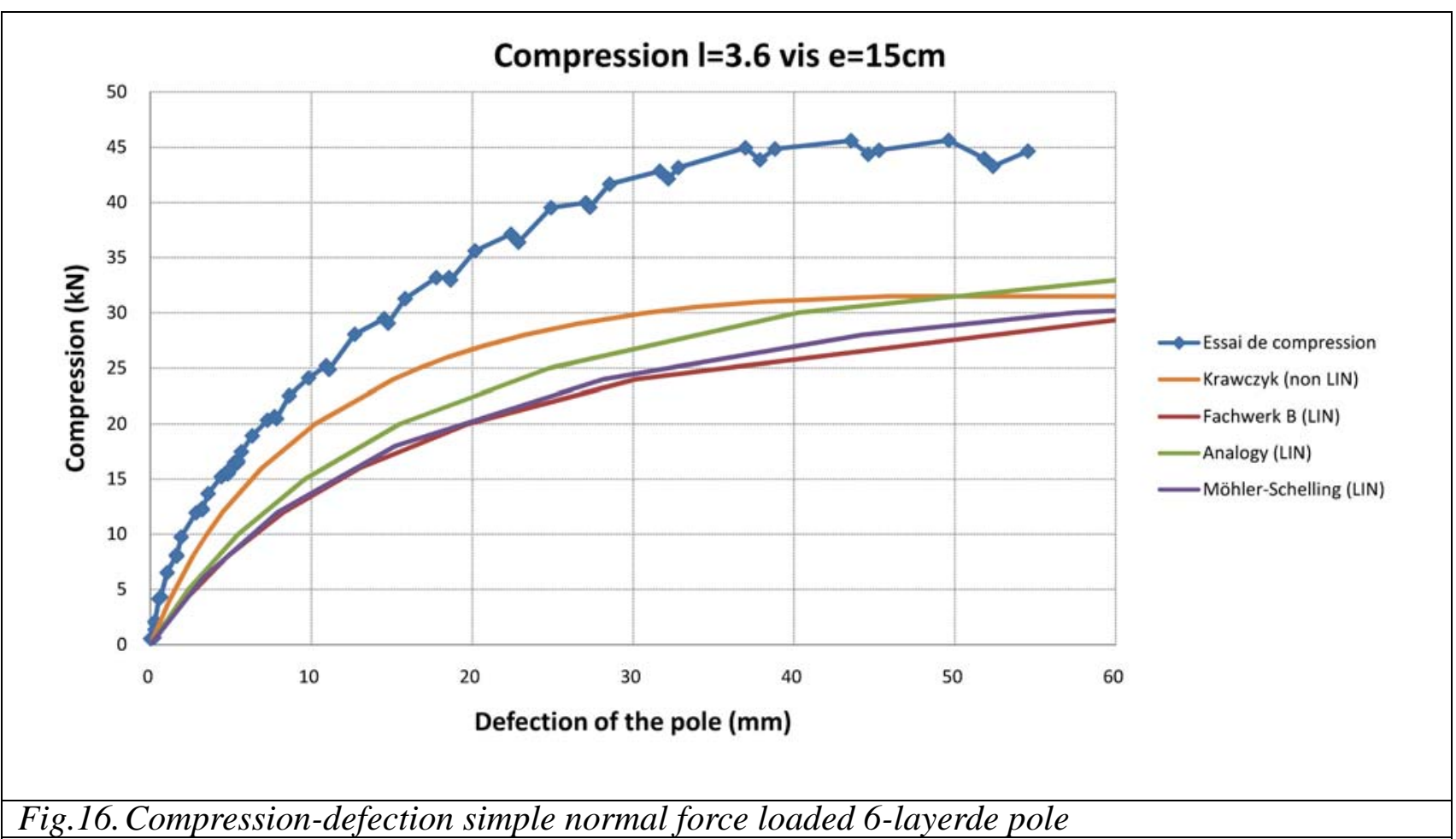




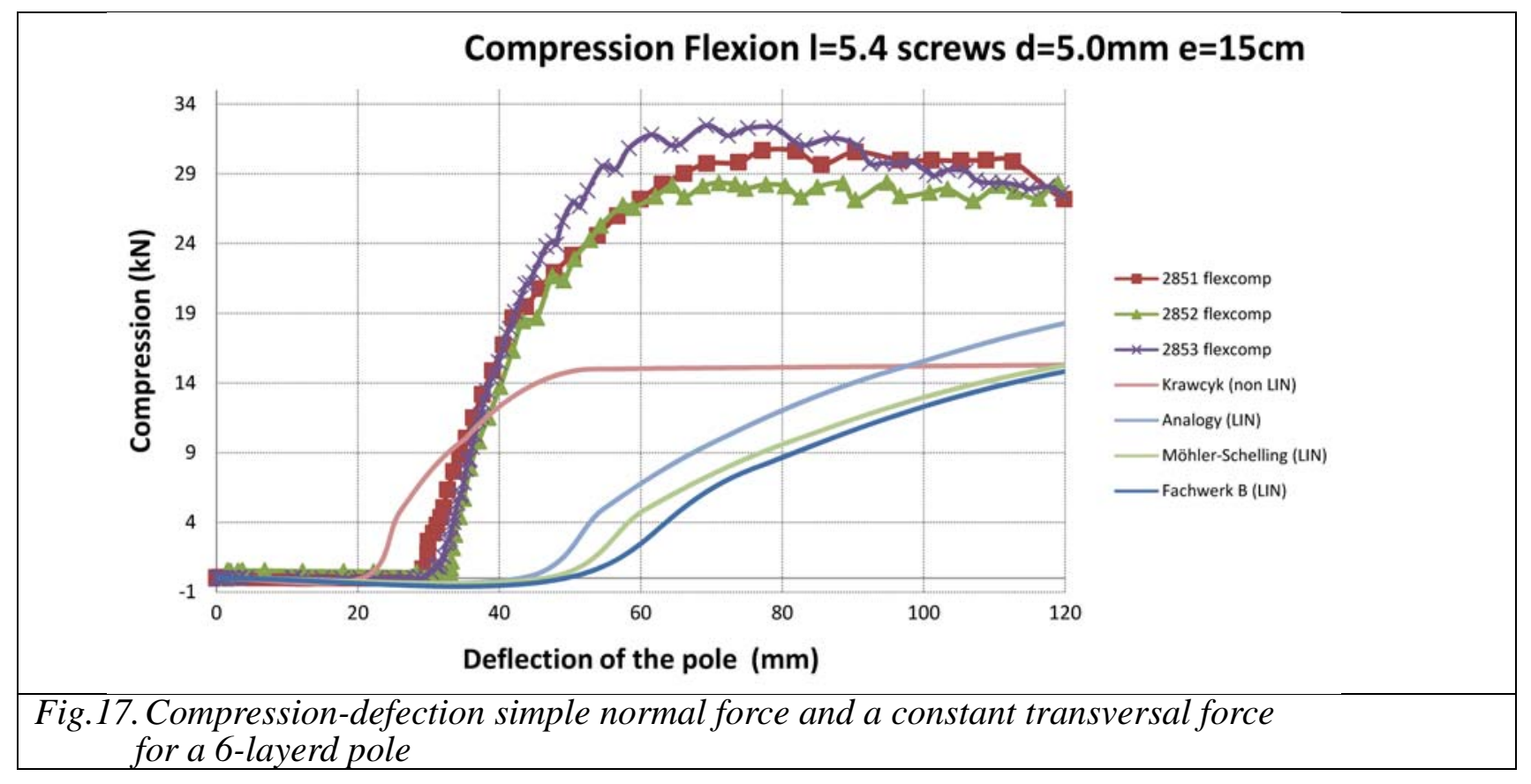

\section{Conclusions}

For the moment the main work of the research tried to optimize the determination of the shear stiffness as near as possible to reality of multy-layered beams. The application of the a non-linear behavior of the joints is showing a large advantage. For the moment the best approximation is the finite element of Krawczyk. Actually it is only 2D, but it is in development for a 3 dimensional use. Furthermore, the laboratory for timber construction of the EPFLwill run load tests on a great scale model for the evaluation of the spatial stability of a ribbed shell.

\section{6. $\quad$ References}

[1] Natterer, J., N. Burger, Müller, A., Natterer Jo. (2001). „The EXPO-roof in Hanover as a pilot project in timber construction, development and application of non-ruled construction methods." Bautechnik 78(10): 693-705.

[2] Möhler, K. (1955). "über das Tragverhalten von Biegeträger und Ruckstäben mit zusamengestzten Querschnitten und nachgiebigen Verbindungsmitteln." Habiliation(TH Karlsruhe).

[3] Schelling, W. (1968). „Die Berechnung nachgiebig verbundener zusammengesetzter Biegeträger im Ingenieurholzbau“. Karlsruhe, Berenz.

[4] Kneidl, R., Hartmann, H (1995). "Träger mit nachiebigem Verbund." Bauen mit holz(04/95): 285-291.

[5] Hartmann, H.: „Die Berücksichtigung elastisch-plastischer Verformungseigenschaften mechanischer Verbindungsmittel bei Verbundkonstruktionen im Ingenieurholzbau2. Dissertation, TU München 1999

[6] Kreuzinger, H. (1999). "Platten, Scheiben und Schalen. Ein Berechnungmodell für gängige Statikprogramme." Bauen mit holz(01/99): 34-39.

[7] Krawczyk, P (2006). "nonlinear analysis of layered structures with weak interfaces" Ph. D thesis, Ecole polytechnique fédérale de Lausanne

[8] Johansen, K.W.: "The Theory of Timber Connections". IABSE - International Association of Bridge and Structural Engineering, Bern. Publikation No. 9 (1949), S. 249-262

[9] Pirazzi, C. (2005). „Zur Berechnung von Holzschalen in Brettrippenbauweise mit elastischem Verbundquerschnitt“. Ph. D. thesis, Ecole polytechnique fédérale de Lausanne.

[10] DIN EN 26 891: „Holzbauwerke - Verbindungen mit mechanischen Verbindungsmitteln; Allgemeine Grundsätze für die Ermittlung der Tragfähigkeit und des Verformungsverhaltens“. Ausgabe: 1991-02

[11] Foschi R, Ricardeo O., Bonac Thomas. "Load-slip characteristics for connections with common nails". Wood Science, Vol. 9, Nr. 31977

[12] Ehlbeck, J., 1979 "Nailed joints in wood structures" No 166, Virginia Polytechnic Institut

[13] Natterer, J. , Weinand Y, (2007/1) "Tragverhalten eines sechsteiliges, nachgiebiges Verbundelement", Holzforschung Schweiz, ss.15-17 